\title{
ICRCCM Phase II: \\ Verification and Calibration of Radiation Codes in Climate Models
}

for the period 1 Novernber 1991 through 1 December $1992^{*}$

Principle Investigator

Robert G. Ellingson

Co-investigators:

Warren J. Wiscombe

David Murcray

William Smith

Richard Strauch from 1 January through 1 November 1991 are appended. 


\section{Introduction}

Following the finding by the InterComparison of Radiation Codes used in Climate Models (ICRCCM) of large differences among fluxes predicted by sophisticated radiation models that could not be sorted out because of the lack of a set of accurate atmospheric spectral radiation data measured simultaneously with the important radiative properties of the atmosphere, our team of scientists proposed to remedy the situation by carrying out a comprehensive program of measurement and analysis called SPECTRE (Spectral Radiance Experiment). SPECTRE will establish an absolute standard against which to compare models, and will aim to remove the "hidden variables" (unknown humidities, aerosols, etc.) which radiation modelers have invoked to excuse disagreements with observation. The data collected during SPECTRE form the test bed for the second phase of ICRCCM, namely verification and calibration of radiation codes used in climate models. This should lead to more accurate radiation models for use in parameterizing climate models, which in turn play a key role in the prediction of trace-gas greenhouse effects.

This report summarizes the activities of our group during the project's Third year to meet our stated objectives. The report is divided into three sections entitled:

\section{SPECTRE Activities, \\ ICRCCM Activities, and \\ Summary Information.}

The section on SPECTRE activities summarizes the field portion of the project during 1991 , and the data reduction/analysis performed by the various participants. The section on ICRCCM activities summarizes our initial attempts to select data for distribution to ICRCCM participants and at comparison of observations with calculations as will be done by the ICRCCM participants. The Summary Information section lists data concerning publications, presentations, graduate students supported, and post-doctoral appointments during the project.

\section{SPECTRE Activities}

\section{SPECTRE Field Phase}

The field phase of SPECTRE was carried out as part of the surface based portion of FIRE Cirrus II at the Coffeyville, KS airport during the period from 12 November through 7 December 1991. The suite of SPECTRE instruments were located on flat terrain on the northern edge of the airport between the active runways. The SPECTRE-funded interferometers were located within $10 \mathrm{~m}$ of one another, and their recording devices were housed in a common trailer. The trace gas sampling unit, the SPECTRE-funded radiosonde launching unit, the Raman lidar, the 404 and $50 \mathrm{MHz}$ RASS units and an NCAR-supplied Portable Automated Meteorological Station (PAMS) were located within $100 \mathrm{~m}$ of the interferometers. The trailers, electricity and necessary supplies were furnished by NASA.

In addition to the SPECTRE instrumentation, many other FIRE participants were located at the SPECTRE site or at the adjacent airport. These include:

Microwave radiometer (for precipitable and liquid water)

IR radiation thermometer

Pyranometers and pyrgeometers (international intercomparison)

PAM station (airport)

Cloud radars (2) 


\begin{tabular}{|c|c|c|c|c|c|c|c|c|c|c|c|c|c|c|c|c|c|c|c|c|c|c|c|c|c|}
\hline & \multicolumn{19}{|c|}{ November } & \multicolumn{6}{|c|}{ December } \\
\hline Group & 12 & 13 & 14 & 15 & 16 & 17 & 18 & 19 & 20 & 21 & 22 & 23 & 24 & 25 & 26 & 27 & 28 & 29 & 30 & 1 & 2 & 3 & 4 & 5 & 6 \\
\hline Interferometers & & & & & & & & & & & & & & & & & & & & & & & & & \\
\hline Wisconsin & $\bullet$ & $\bullet$ & & & & $\bullet$ & $\bullet$ & & $\bullet$ & $\bullet$ & $\bullet$ & $\bullet$ & - & $\bullet$ & $\bullet$ & $\bullet$ & $\bullet$ & $\bullet$ & & & & $\bullet$ & - & $\bullet$ & $\bullet$ \\
\hline Denver - IR & & $\bullet$ & & & & - & $\bullet$ & & - & $\bullet$ & $\bullet$ & $\bullet$ & $\bullet$ & $\bullet$ & $\bullet$ & $\bullet$ & & & & & & $\bullet$ & $\bullet$ & $\bullet$ & $\bullet$ \\
\hline GSFC & & & & & & & $\bullet$ & & - & $\bullet$ & - & - & - & - & - & $\bullet$ & - & $\bullet$ & & & & $\bullet$ & $\bullet$ & $\cdot$ & $\bullet$ \\
\hline Denver - SW & & & & & & $\bullet$ & - & & - & - & & $\bullet$ & - & & & & & & & & & $\bullet$ & - & - & $\bullet$ \\
\hline & & & & & & & & & & & & & & & & & & & & & & & & & \\
\hline Remote Sensors & & & & & & & & & & & & & & & & & & & & & & & & & \\
\hline Raman & & $\bullet$ & & & & $\bullet$ & $\bullet$ & & $\bullet$ & $\bullet$ & & $\bullet$ & $\bullet$ & - & & & & - & & & & $\bullet$ & $\bullet$ & $\bullet$ & $\bullet$ \\
\hline RASS $404 \mathrm{Mh}$ & & - & - & - & $\bullet$ & $\bullet$ & - & $\bullet$ & & - & - & - & - & - & - & • & $\bullet$ & & $\bullet$ & $\bullet$ & $\cdot$ & - & $\bullet$ & 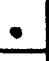 & $\bullet$ \\
\hline & & & & & & & & & & & & & & & & & & & & & & & & & \\
\hline Insitu & & & & & & & & & & & & & & & & & & & & & & & & & \\
\hline Soundings & & $\bullet$ & & & & $\bullet$ & $\bullet$ & & - & $\bullet$ & - & $\bullet$ & - & - & - & - & - & $\bullet$ & & & & - & $\bullet$ & - & $\bullet$ \\
\hline Trace Gases & & - & & & & $\bullet$ & - & & $\bullet$ & $\bullet$ & $\bullet$ & $\bullet$ & - & $\bullet$ & $\bullet$ & & - & & - & & & & $\bullet$ & - & $\bullet$ \\
\hline
\end{tabular}

Fig. 1. SPECTRE observation days during FIRE Cirrus II. The • 's indicate days on which the instruments were operating.

Imaging lidars (3) (visible and IR)

All-sky cloud imaging devices (2)

IR interferometer and spectrometer

CLASS radiosonde launch facility

Cloud replicator sondes

The days of operations of the various platforms and the typical schedule followed for the launching sondes during SPECTRE operations are shown in Figs. 1 and 2 , respectively. The emission interferometers usually operated continuously between local noon and midnight, whereas the Raman lidar typically operated between sunset and sunrise. Absorption interferometer measurements were obtained during clear daylight periods by the Denver group, Dobson measurement were obtained near local noon when possible, and flask samples of trace gases were collected at least twice per day.

Originally, we had planneu' to deploy a tethersonde to measure temperature, humidity and ozone in the lowest $300 \mathrm{~m}$. Unfortunately, the FAA ruled in October 1991 that we could not fly the tethersonde at the airport. Therefore, we arranged for more frequent launches of radiosondes throughout the observation period. Combined with the FIRE-launched sondes, soundings of the atmosphere were obtained at about two hour intervals. 


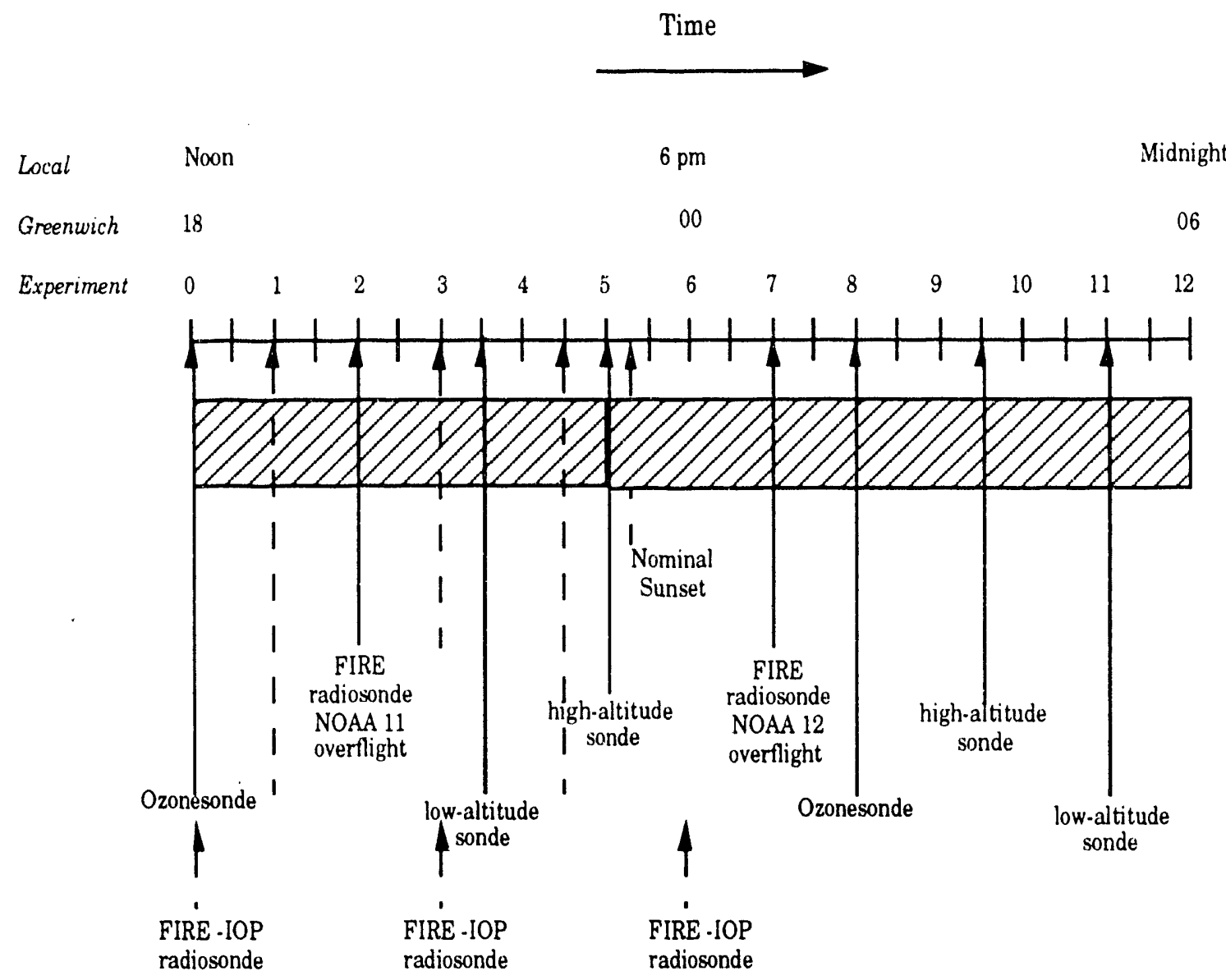

Fig. 2. SPECTRE observation schedule.

The field phase proceeded relatively smoothly, and we encountered many clearsky periods as well as several with near-homogeneous overcasts of cirrus, middle and low-level clouds. Fortunately, Mother Nature cooperated and gave us good observing conditions that spanned a wide range of conditions. For example, the surface temperature and the integrated precipitable water ranged from about 0 to $23^{\circ} \mathrm{C}$ and 0.5 to $2.5 \mathrm{~cm}$, respectively. With the exception of the $50 \mathrm{Mhz}$ RASS, all of the instruments appeared to perform up to our expectations under field conditions, and several thousand spectra of the 3 to $20 \mu \mathrm{m}$ region were obtained by the three interferometers.

We were also able to accomplish a partial in-field intercalibration of the radiometers using a calibrated black body furnished by the NASA group. The black body was taken to Denver and to Wisconsin to complete the instrument intercalibration. Overall, tests in the fields and subsequent analysis at the home institutions showed that the various interferometers collected useful information on all of the days listed in Fig. 1. The Denver and Wisconsin groups estimate a relative accuracy of the order of $0.1 \%$ and an absolute accuracy approaching $1 \%$ of the maximum signal for the spectral region extending from about 550 to $3000 \mathrm{~cm}^{-1}$. The NASA group estimates a relative accuracy of the order of 0.3 to $1 \%$ for different spectral intervals the 700 to $2000 \mathrm{~cm}^{-1}$ region. Therefore, we expect the data to allow more accurate tests of radiation models over a wide range of atmospheric variables than possible heretofore. 


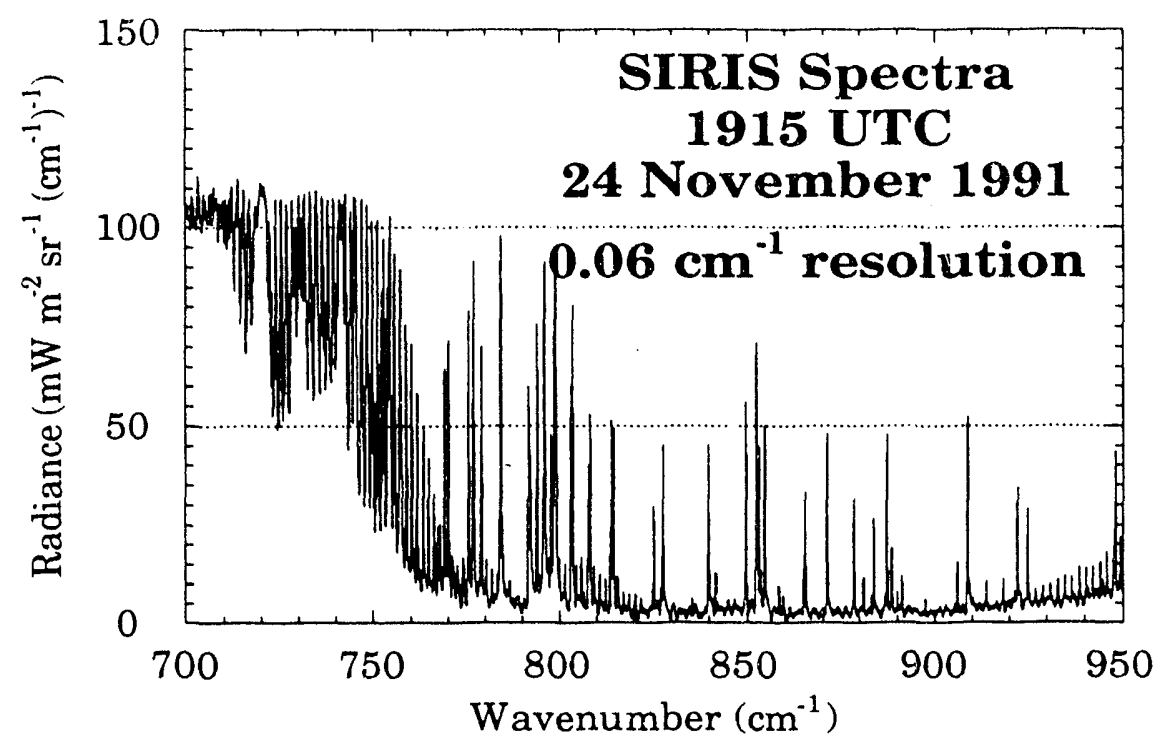

Fig. 3. Example of a SIRIS spectrum for the $700-950 \mathrm{~cm}^{-1}$ region.

\section{Data Analysis}

The Wisconsin and Denver groups have produced a calibrated data set for each of the observation days, and the NASA Goddard group has produced preliminary calibrations for several selected days. The calibrations are being refined at this time to remove some previously unknown non-linearities in the Wisconsin and Denver instruments. The re-calibrated data are expected to be available around January 1 , 1993 from the Wisconsin and Denver groups and around October 1, 1993 from the NASA Goddard group. Examples of data from the interferometers are shown in Figs. 3 and 4.

As seen from Fig. 3, the $0.06 \mathrm{~cm}^{-1}$ resolution of the SIRIS (NASA) instrument allows the identification of individual lines, and it allow a better view of regions between strong lines than is possible with the Wisconsin (AERI) and Denver instruments. Fig. 4 shows that the Wisconsin and Denver measurements agree quite well over most of the spectrum, although there are differences in the 800 to $1200 \mathrm{~cm}^{-1}$ region. Some of these are due to the different resolutions of the instruments, whereas others are due to differences in the calibration procedures. When the final calibrations of all of the spectra are completed, these types of differences will enable the setting of more realistic error bars than have been possible in previous experiments.

The major disappointment from the experiment was the failure of the $50 \mathrm{Mhz}$ RASS. The RASS was installed and was operating during the experiment. However, significant electronic noise problems were found at the beginning of the field phase, and it proved to be impossible to remove them during the course of the experiment or in subsequent analysis. Thus we will be forced to use radiosonde measured temperatures for altitudes above about $2 \mathrm{~km}$ for all of the analyses. However, since we increased the frequency of radiosonde launches to fill in the gap caused by the lack of a tethersonde, we have excellent temperature data at about two hour intervals. 


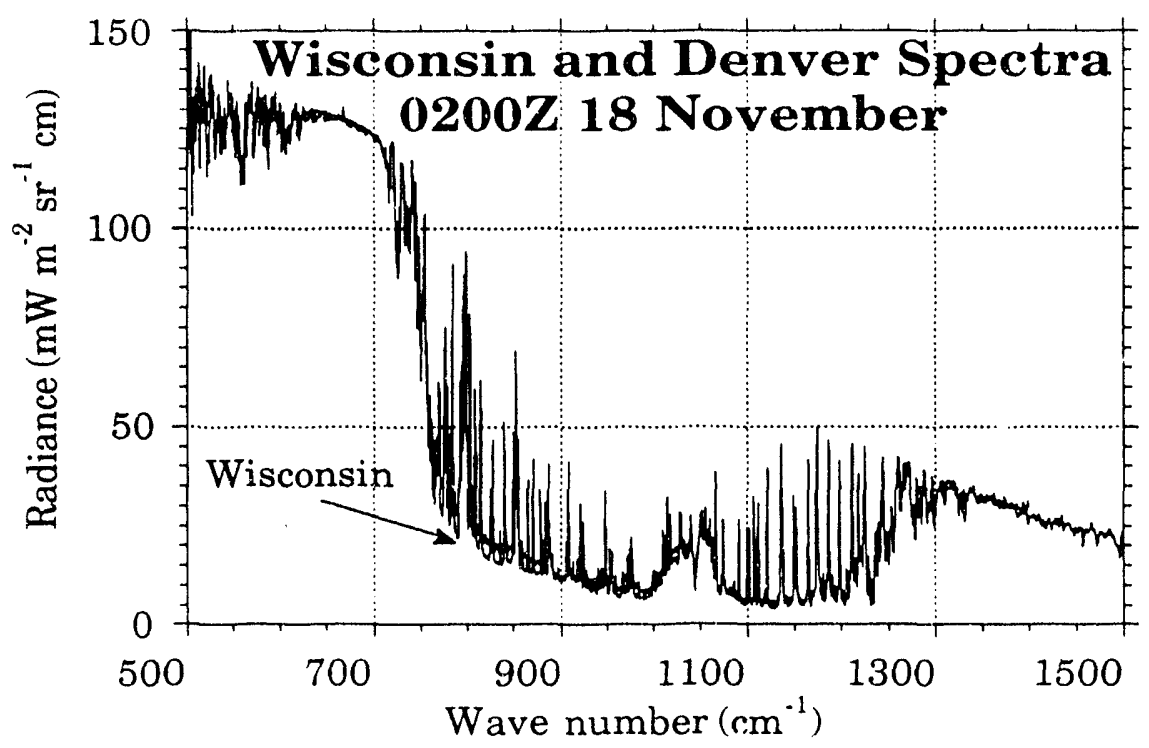

Fig. 4. A comparison of near-simultaneous spectra observed by the Wisconsin and Denver interferometers for the 500 to $1500 \mathrm{~cm}^{-1}$ region.

The $404 \mathrm{Mhz}$ RASS operated well throughout the project, although high winds at the site limited the recovery of data to an altitude of about $1 \mathrm{~km}$ on many occasions. One unexpected result was that the NOAA group led by Strauch was able to explain the interaction between horizontal winds and turbulence in RASS measurements. The model they have developed is described in a recently completed Ph.D. dissertation by R. Lataitis (see below). The $404 \mathrm{MHz}$ RASS data are being edited, and the data will be merged into a continuous time-height temperature field. This product is expected to be completed by the end of calendar 1992.

Data from the Wallops-launched radiosondes, Dobson spectrometer, ozonesondes and flask samples have reduced and quality checked, and they are available for use in model calculations. Summary results from some of the trace gas measurements are shown in Figs. 5 and 6 Briefly, rather large day-to-day variations of ozone were found in the lower troposphere as well as for the total column content. Furthermore, the concentrations of $\mathrm{CO}_{2}$ and $\mathrm{CH}_{4}$ were found to vary over a relatively large range and were not constant with altitude below about $1.5 \mathrm{~km}$. Measurements of these variations will be particularly important in understanding comparisons between the observations and calculations.

The Raman lidar data have been reduced to yield vertical profiles of the tropospheric $\mathrm{H}_{2} \mathrm{O}$ mixing ratio and the tropospheric and stratospheric aerosol backscatter at approximately $100 \mathrm{~m}$ resolution at ten minute intervals (i.e., roughly the time intervals for spectra). We've begun to intercompare radiosonde and Raman $\mathrm{H}_{2} \mathrm{O}$ soundings as well as their effects on radiation calculations. Some significant differences have been found, and our preliminary analysis indicates that the Raman soundings with the radiosonde temperatures give a more consistent set of comparisons with the observations than occurs with the radiosonde data. We plan to study this problem in considerably more detail during the next year.

An unexpected occurrence before the experiment was the eruption of Mt. Pinatubo. The Raman lidar noted several occasions of stratospheric aerosol dur- 


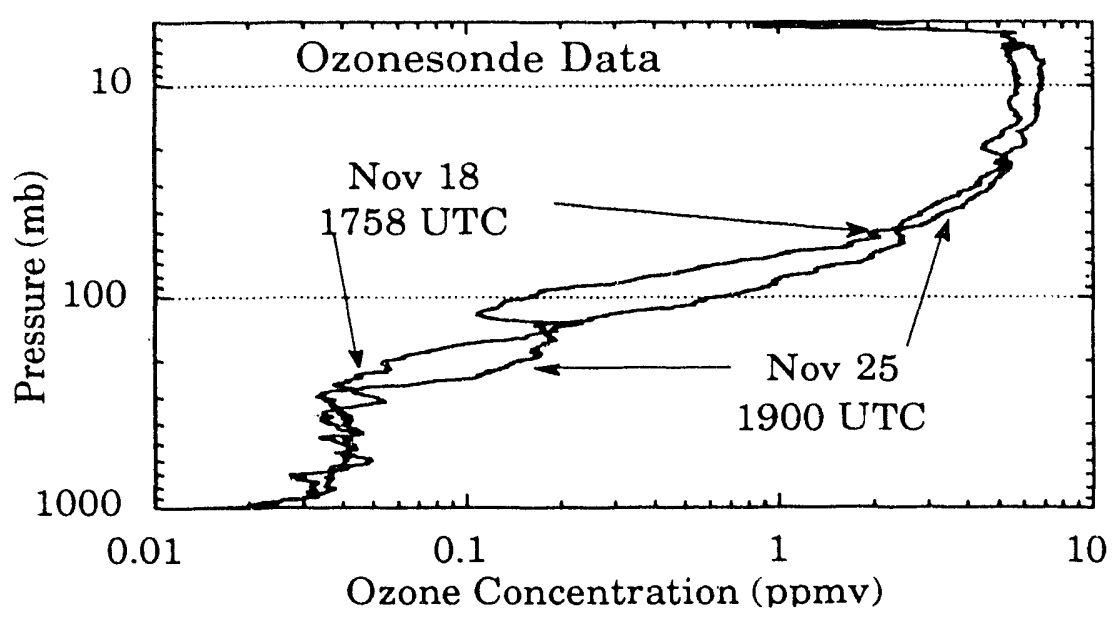

Fig. 5. Examples of ozone soundings.

ing the experiment, and these are summarized in a paper by Ferrare et al. (1992) (see below). The Raman observations along with sun photometer data may be useful in determining whether disagreements between observed and calculated spectra are related to variations in the stratospheric aerosol.

\section{ICRCCM Activities}

\section{Preliminary Comparisons of Observations With Calculations}

As the first step for selecting data for distribution to ICRCCM and ITRA (ITRA - Intercomparison of Transmittance and Radiance Algorithms) participants, the SPECTRE team examined the variability of the observed spectra and observations of the surface temperature, the column precipitable water and cloudiness to select four clear and one homogeneous cirrus overcast case study periods which were representative of the range of variables during the observational period. Summary information for these periods is given in Table 1. Examples of spectra from the Wisconsin AERI instrument (preliminary calibration) for the Cold-Wet, Cold-Dry, Warm-Wet and Cirrus cases are shown in Fig. 7.

We have begun to compare the observed spectra with line-by-line and narrowband radiation models as will be done by the various ICRCCM and ITRA participants. Examples of such comparisons for the Warm-Wet and Cold-Dry case study days are shown in Fig. 8. The calculations were performed with the line-by-line model FASCODE3P using near simultaneous radiosonde and trace gas data and the 1992 line compilation as input.

In general, the line-by-line model captures most of the features in the observed clear-sky spectra. There is a tendency for the model to underestimate the observed radiance in the window region between 800 to $1000 \mathrm{~cm}^{-1}$ and to overestimate it in portions of the 1200 to $1400 \mathrm{~cm}^{-1}$ region. However, we are not yet in the position to make firm conclusions concerning the spectral and absolute character of the differences because the final instrument calibration is not yet 


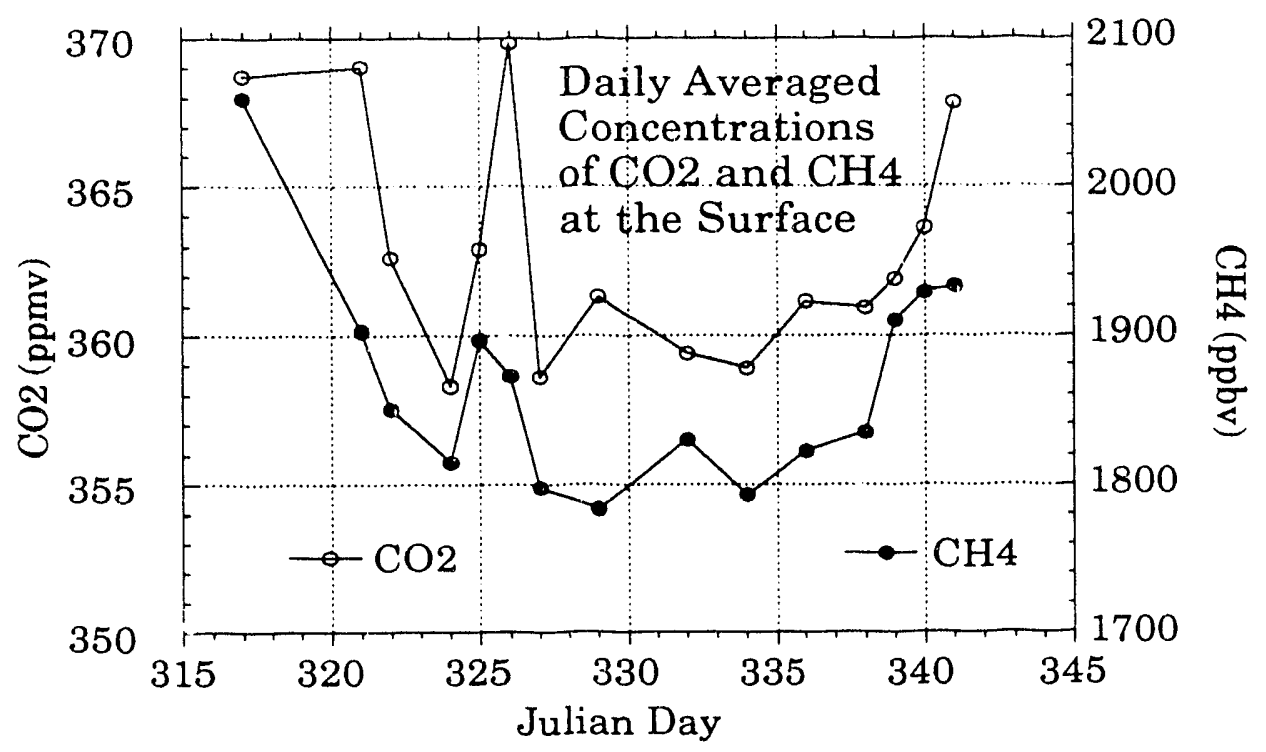

Fig. 6. Surface concentrations of $\mathrm{CO}_{2}$ and $\mathrm{CH}_{4}$ during SPECTRE.

complete and because we have not had the opportunity to study the effects of using all of the Raman water vapor profiles and the RASS observation in the calculations

Our sensitivity analysis of the radiation calculations shows that with the expected $5 \%$ humidity and $0.5 \mathrm{~K}$ temperature accuracies, the uncertainties in the calculations due to errors in the meteorological data should be kept below about $8 \%$ in the regions of relatively strong lines and below about $5 \%$ in weakly absorbing regions. In the transparent region of the spectrum from 800 to $1000 \mathrm{~cm}^{-1}$, narrow-band model radiances calculated using the Roberts et al (1976) continuum and those using the more recent continuum of Clough et al (1989) used in FASCODE differ by about 30\%, and they show a particular spectral signal. Assuming an absolute radiance error of the order of $1 \%$ full scale, the differences between the observed and calculated spectra in the 800 to $1000 \mathrm{~cm}^{-1}$ region for the Warm-Wet day indicate that the FASCODE continuum yields better results than the one of Robert's. The data from the cold-dry

Table 1. - SPECTRE case study periods.

\begin{tabular}{|c|l|l|c|c|}
\hline Name & \multicolumn{1}{|c|}{$\begin{array}{c}\text { Date } \\
1991\end{array}$} & Cloudiness & $\begin{array}{c}\text { Surface } \\
\text { Temperature } \\
\left({ }^{\circ} \mathrm{C}\right)\end{array}$ & $\begin{array}{c}\text { Precipitable } \\
\text { Water } \\
(\mathrm{cm})\end{array}$ \\
\hline Warm-Wet & $18-19$ Nov. & Clear & 22 & 2.0 \\
\hline $\begin{array}{c}\text { Intermediate } \\
\text { T and H2O }\end{array}$ & 26 Nov. & Clear & 10 & 1.2 \\
\hline Warm-Dry & 30 Nov. & Clear & 22 & 0.6 \\
\hline Cold-Dry & $03-04$ Dec. & Clear & 0 & 0.7 \\
\hline Cold Wet & 05 Dec. & Clear \& Cirrus & 0 & 0.9 \\
\hline
\end{tabular}




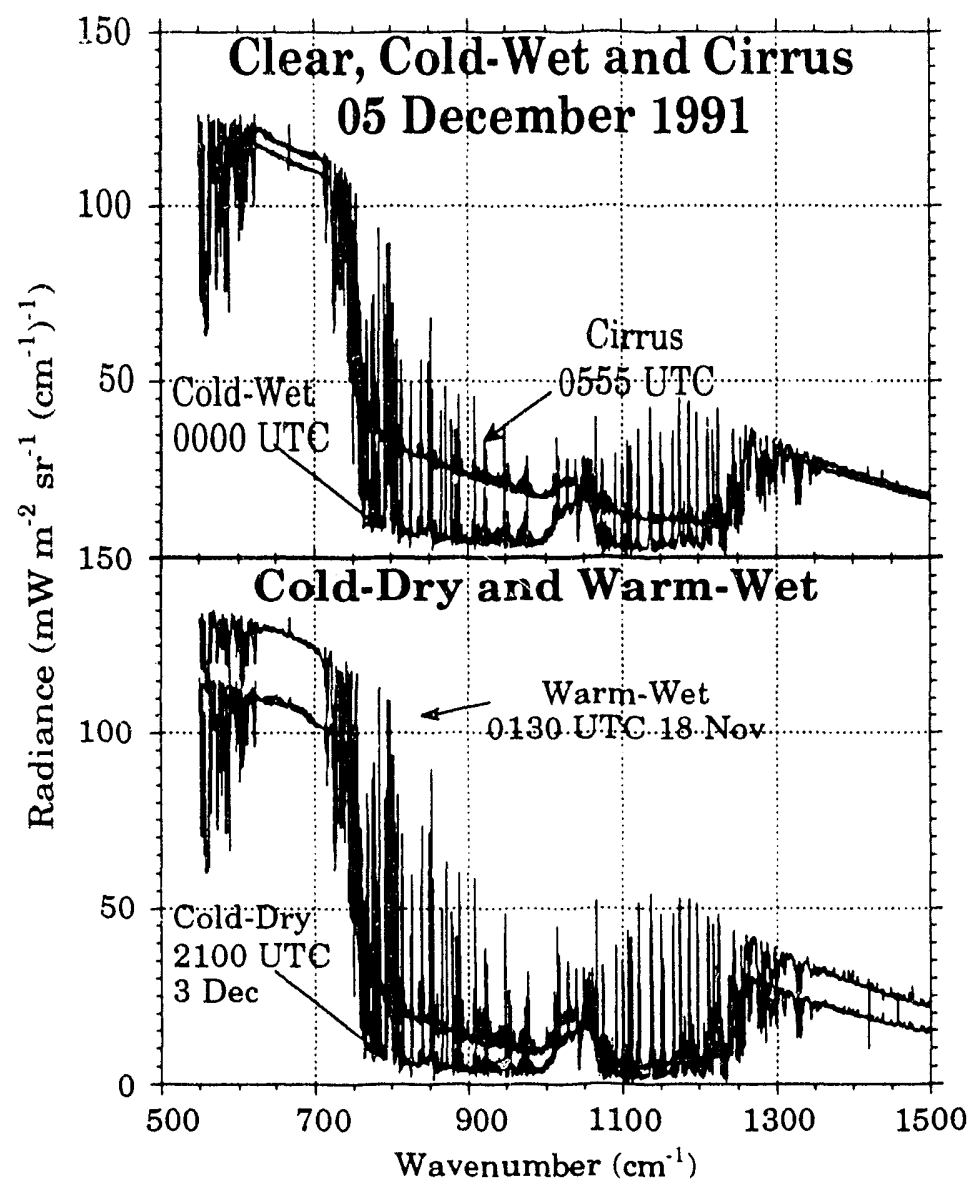

Fig. 7. Examples of spectra from the case study periods.

case can not be use to support this conclusion at this time because the absolute error of the observations is larger than the radiance in the more transparent regions of the 800 to $1000 \mathrm{~cm}-1$ region. However, as the instrument calibrations are completed, it will be possible to use the high relative accuracy to check the spectral signatures of the differences and to put error bars on them .

We recently completed six sets of comparisons of AERI observations with FASCODE calculations using water vapor data from both radiosonde and simultaneous Raman lidar observations. Those comparisons show that the Raman data yield a more consistent spectral pattern of differences between observations and calculations than occurs when the radiosonde data are used in the calculations. As the calibrations of the different instruments are completed, it will be possible to use the high relative accuracy of the observations to check the spectral signatures of the differences between observations and calculations and to put error bar's on the absolute differences. The new calibration data and the Raman water vapor data should allow more stringent tests of the continuum formulations than possible heretofore. 


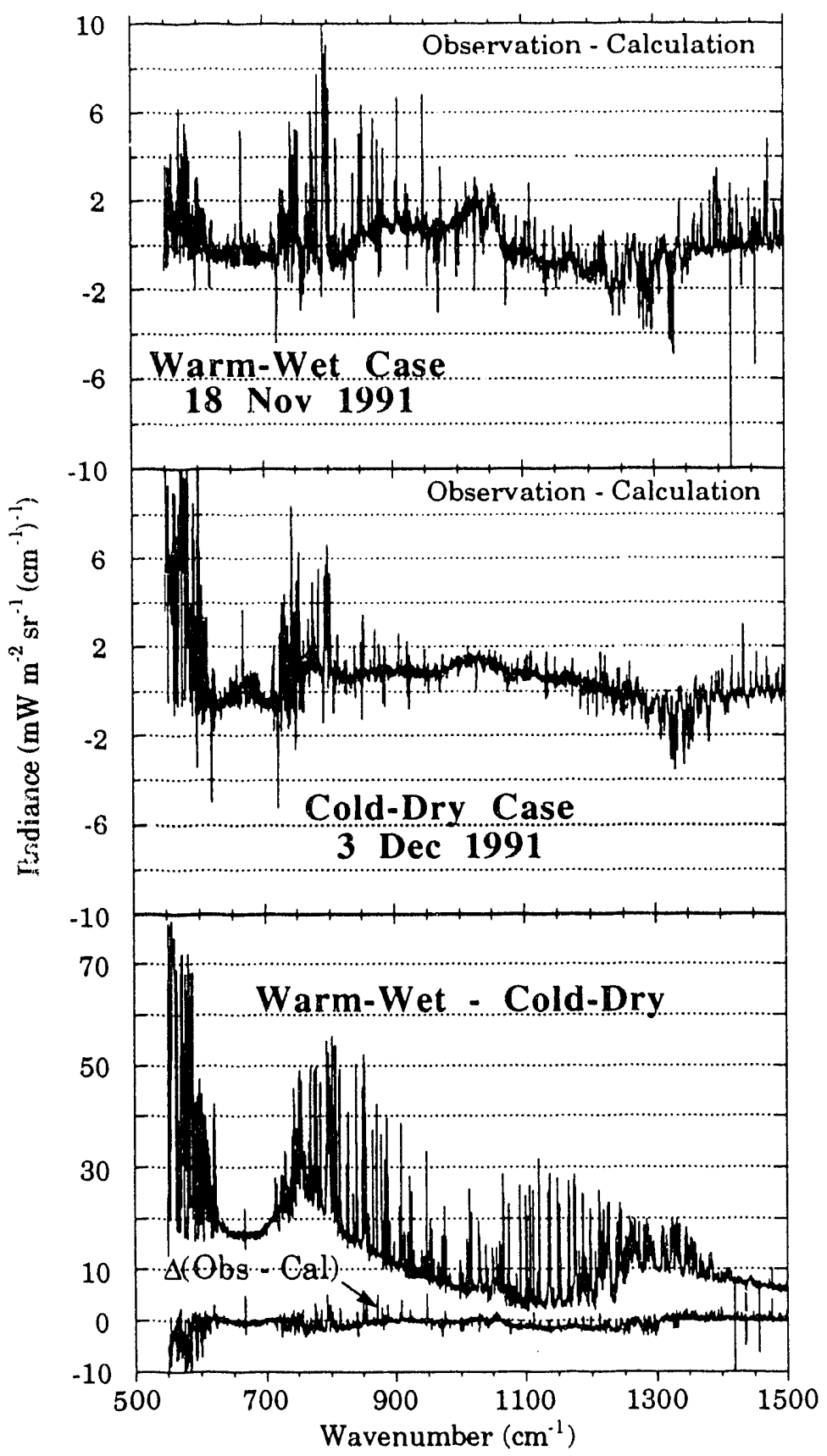

Fig. 8. Comparisons of observed with calculated spectra for the WarmWet and Cold-Dry cases. Also shown in are the differences between the two spectra relative to the differences between the observations and calculations. 


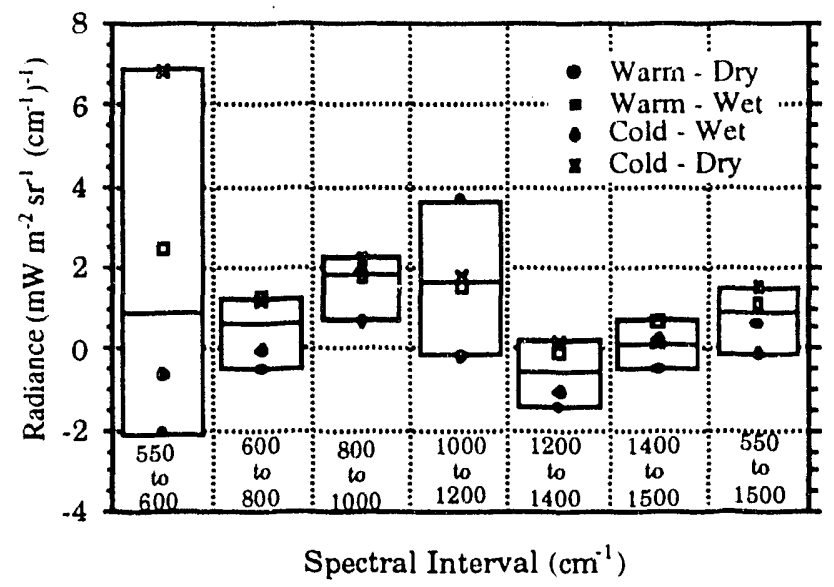

Fig. 9. Observed minus calculated integrated spectral radiance for the four priority days. Observations employ the preliminary calibration.

In addition to the absolute value of radiance, climate modelers are also interested in determining the accuracy of their parameterizations to changes in atmospheric variables. Unfortunately, it is not possible to observe the partial derivatives that modelers often calculate. Nevertheless, it is interesting to evaluate differences between observed and calculated spectra obtained under different atmospheric conditions because these test the ability of models to calculate total derivatives. Shown also in Fig. 8 is the spectrum of the differences between the observed Warm-Wet and Cold-Dry spectra and the spectrum of the differences between the observed and (radiosonde) calculated spectra for the two cases $(\Delta(\mathrm{Obs}-\mathrm{Cal}))$. With the exception of the region between 1100 and $1300 \mathrm{~cm}^{-1}$, the majority of the spectral differences fall between $\pm 10 \%$ of the observed spectral changes. These results are quite encouraging, and we expect to be able to place quantitative estimates on the total derivatives with the finalized data set. Such difference may also prove useful in tests of continuum formulations since they remove residual systematic errors in the radiance observations.

Climate modelers are also anxious to test the ability of their radiation codes to calculate the total downward flux. Until SPECTRE, modelers have had to rely upon pyrgeometers which have an accuracy of the order of $\pm 5 \%$. The radiance observations can be integrated over the spectrum to yield estimates of the flux uncertainty for the observed portion of the spectrum. A summary of the spectrally integrated differences between the observed and calculated radiances for selected spectral regions on the four clear-sky test cases is shown in Fig. 9. When integrated over the 550 to $150 \mathrm{~cm}^{-1}$ interval, and assuming isotropy, the comparisons indicate the flux uncertainty of FASCODE when radiosonde data are used in the calculations to be about $\pm 3 \mathrm{~W} / \mathrm{m}^{2}$.

We are in the process of using FASCODE to obtain a better estimate of the flux uncertainty for the entire spectral region (i.e., 550 to $3000 \mathrm{~cm}^{-1}$ ) observed by the interferometers. Note that for a given plane parallel, horizontally homogeneous at- 
mosphere, the downward flux may be related to the vertically downward radiance $\mathrm{I}(0)$ as $\mathrm{F}=\pi \mathrm{I}(0) \mathrm{L}$ where

$$
\mathrm{L}=\int_{0}^{1} \frac{\mathrm{I}(\mu)}{\mathrm{I}(0)} \mu \mathrm{d} \mu
$$

$\mu=\cos \theta$, and $\theta$ is the local zenith angle.

To first order, we assume $L$ to be a property of the temperature and water vapor distributions and not of the ability to calculate I. Thus, the soundings may be used with FASCODE to calculate L, and the uncertainty in F for the observed spectral interval is given approximately as

$$
\delta \mathrm{F}=\pi \mathrm{L}\left(\mathrm{I}_{\mathrm{obs}}(0)-\mathrm{I}_{\mathrm{cal}}(0)\right) .
$$

Note that this is a better approximation than assuming isotropy or assuming the validity of the diffusivity approximation (i.e., $\left.\mathrm{L}=\mathrm{I}\left(53^{\circ}\right) / \mathrm{I}(0)\right)$ ) which is used in most climate models.

The data do not allow us to estimate the uncertainties in the 0 to $550 \mathrm{~cm}^{-1} \mathrm{re}$ gion. However, since this portion of he spectrum is nearly opaque for the conditions we observed during FIRE, the unctainties in calculating the downward flux at the surface from this portion of the spectrun? are relatively small. Thus, we plan to estimate the flux for homogeneous clear and cloudy conditions with model calculations for the 0 to $550 \mathrm{~cm}^{-1}$ region and with Eq. (1) for the 550 to $3000 \mathrm{~cm}^{-1}$ region and compare the results with observations from the pyrgeometers located at the SPECTRE site as part of an international intercomparison project. Since the uncertainties in the interferometer data are smaller than those associated with the pyrgeometers, we be:lieve that the interferometer-based flux data will serve as a baseline calibration of the pyrgeometers.

\section{Correspondence with ITRA}

Ellingson presented the preliminary results from SPECTRE to the paricipants of the ITRA Workshop held in Helsinki, Finland prior to the IRS'92. The ITRA working group, like ICRCCM, is sanctioned by the International radiation Commission. The ITRA participants are anxious to use the SPECTRE data since there are few data set which will allow the testing of their line-by-line and narrow band radiation models. The same or similar models are being used by some of the ICRCCM participants to develop more highly parameterized models for climate studies. ICRCCM benefited greatly from its previous contacts with ITRA, and we expect that their use of the SPECTRE data will benefit both working groups.

\section{Summary Information}

\section{Students Supported and Degr ses Completed}

Name: Paul Delaney

Degree: M.S.

Date: $\quad$ August 1991

Institution: University of Maryland

Title of Thesis or Scholarly Paper

Sensitivity of Atmospheric Radiation to Temperature, Water vapor and Ozone rofiles 
Name: Wayne Feltz

Degree: M.S.

Date:

Institution: University of Wisconsin

Name: Pierre Fogal

Degree: Ph.D.

Date: $\quad$ Spring 1993

Institution: Denver University

Name: R. J. Lataitis

Degree: Ph.D.

Date: December 1992

Institution: University of Colorado

Title of Thesis or Scholarly Paper

Theory and $\ell$ pplication of a Radio-Acoustic Sounding System (RASS)

Name: Dejiang Han

Degree: M.S.

Date: August 1993

Institution: University of Maryland

Title of Thesis or Scholarly Paper

Estimation of Downward flux at the Surface from AERI Radiance Observations

Name: Ranate Van Allen

Degree: Ph.D.

Date: $\quad$ Spring 1993

Institution: Denver University

Name: Paul Sullivan

Degree: M.S.

Date:

Institution: Denver University

Post-doctoral Fellows Supported

University of Maryland

Keith Knoll

Experiment planning

Dr. Suhung Shen

Spectral radiation observation analysis, meteorological data analysis

University of Wisconsin

Jean Marc Theriaux,

Quebec Canada

Instrument Design, Field Data Collection,Aerosol Sensitivity Studies

Paul Van Delst

Perth Australia

Instrument software development, field data collection, trace gas retrieval

Publications (completed and/or in progress) 
Delaney, P., 1991: Sensitivity of Atmospheric Radiation to Temperature, Water vapor and Ozone rofiles. Scholarly Paper, Dept. of Meteorology, University of Maryland, May 1991, (to be submitted to J. Quant. Spec. Rad. Trans., Jan. 1993) 22pp.

DeLuisi, J., 1992: BSRN, Broadband IR Radiometer Intercomparison, Coffeyville, KS, 13 Nov. -7 Dec. 1991. Preliminary Data Results, NOAA/CMDL, 325 Broadway, Boulder, CO. 80303, 60pp.

Ellingson, R. G. and Y. Fouquart, 1991: The intercomparison of radiation codes in climate models (ICRCCM): An overview. J. Geophys. Res., 96, 8926-' '9.

Ellingson, R. G., J. Ellis and S. Fels, 1991: The intercomparison of radiation cudes in climate models (ICRCCM): Longwave results. J. Geophys. Res., 96, 89298953.

Ellingson, R. G., W. J. Wiscombe, J. DeLuisi, V. Kunde, H. Melfi, D. Murcray, and W. Smith, 1993: The SPECTral Radiation Experiment (SPECTR F Clear-sky observations and their use in ICRCCM and ITRA. To appear in the Proceedings of the International Radiation Symposium, IRS'92, 3-8 Aug. 1992, Tallinn, Estonia. (extended version in progress for submission to Bull. Amer. Meteor. Soc., 1993)

Ferrare, R. A., S. H. Melfi, D. N. Whiteman, and K. D. Evans, 1992: Raman lidar measurements of Pinatubo aerosols over southeastern Kansas during November-December 1991, Geophys. Res. Letters, 19, 1599-1602.

Knuteson, R. O., H. E. Revercomb, W. L. Smith, and F. A. Best, 1992: High Spectral Resolution Measurement of Atmospheric Emission: Coincident Upwelling and Downwelling Observations. To appear in the Proceedings of the International Radiation Symposium, IRS'92, 3-8 Aug. 1992, Tallinn, Estonia.

Lataitis, R. J.,1992: Signal power for radio acoustic sounding of temperature: The effects of horizontal winds, turbulence, and vertical temperature gradients. Radio Science, 27, 369-385.

Smith, W. L., R. O. Knuteson, S. A. Ackerman, Ma Xia Lin, and H. E. Revercomb, 1993: Algorithms for Estimating Cloud Optical Properties and Boundary Layer Temperature and Moisture Profiles from ARM Groundbased FTIR Measurements. To appear in the Proceedings of the session on the Atmospheric Radiation Measurement program. AMS 73rd Annual Meeting. Anahei $i$, E, Jan. 1993.

Smith, W. L., R. O. Knuteson, H. E. Revercomb, F. Best, R. Dedecker, H. Howell, 1993: GB-HIS: A Measurement System for Continuous Profiling of Boundary Layer Thermodynamic Structure. To appear in the Proceedings of the Fourth Symposium on Global Change Studies. AMS 73rd Annual Meeting. Anaheim, CA, Jan. 1993.

Wang, W-C., J. London, I. Isaksen, K. Shine, R. Ellingson, and F. Taylor, 1992: Summary report of the IUGG-IAMAP Workshop MW5: Climatic Effects of Atmospheric Trace Constituents, Vienna, 19-20 August 1991. Bull. Amer. Meteor. Soc., 73, 801-804. 


\section{Presentations}

Ellingson, R. G., 1991, Results from the ICRCCM Trace Gas Study. Invited paper presented at the IUGG-IAMAP Workshop on Climatic Effects of Atmospheric Trace Constituents, 19-20 August 1991. Vienna, Austria.

Ellingson, R G., W. J. Wiscombe, J. DeLuisi, V. Kunde, H. Melfi, D. Murcray, and W. Smith, 1992: The SPECTral Radiation Experiment (SPECTRE): An Overview, preliminary results and use in interpretation of ARM Data. Papers by this or similar titles have been presented at the:

Session on Radiative Forcing of Climate and Global Warming Potentials, AGU Spring Meeting, 12-15 May, Montreal, Canada, 15th Annual Review Conference on Atmospheric Transmissions Models, 2-4 June, Phillips Laboratory, Hanscom Air Force Base, MA, 1992 Workshop of the IRC Working Group on Intercomparison of Transmission and Radiance Algorithms, July 1992, Helsinki, Findland, International Radiation Symposium, IRS'92. 3-8 Aug. Tallinn, Estonia, and updated results will be presented at the Fourth Symposium on Global Change Studies. AMS 73rd Annual Meeting. Anaheim, CA. Jan. 1993.

Evans, K, S. H. Melfi, R. Ferrare, D. Whiteman, 1992: Water Vapor Variance Measurements Using a Raman Lidar, Presented at the Specialty Meeting on Airborne Radars and Lidars, 7-10 July, Toulouse, France.

Evans, K. D., S. H. Melfi, R. A. Ferrare, D. N. Whiteman, 1993: Tropospheric temperature measurements using a Raman lidar. To be presented at the 1993 Conference of the Optical Society of America.

Knuteson, R. O., H. E. Revercomb, W. L. Smith, and F. A. Best, 1992: High Spectral Resolution Measurement of Atmospheric Emission: Coincident Upwelling and Downwelling Observations. Presented at the International Radiation Symposium, IRS'92. Tallinn, Estonia. Aug. 3-8, 1992.

Knuteson, R. O., H. E. Revercomb, W. L. Smith, H. Buijs, R. Dedecker, H. B. Howell, H. M. Woolf, S. A. Ackerman, 1991: Realization of a Low-Cost Ground Based Temperature, Humidity, and Trace Gas Profiling System. Presented at the AMS 71st Annual Meeting. New Orleans, LA. Jan 13-18, 1991.

Lataitis, R. J., Temperature Errors in RASS Caused by Winds and Turbulence. 1993: To be presented at the 26th International Conference on Radar Meteorology, Norman, OK, 24-28 May 1993.

Melfi, S. H., D. Whiteman, R. Ferrare, K. Evans J. E. M. Goldsmith, M. Lapp, and S. E. Bisson, 1992: Raman lidar measurements of water vapor and aerosol/clouds during the FJRE/SPECTRE field campaign. Presented at the Specialty Meeting on Airborne Radars and Lidars, 7-10 July, Toulouse, France.

Smith, W. L., R. O. Knuteson, H. E. Revercomb, F. Best, R. Dedecker, H. Howell, 1993: GB-HIS: A Measurement System for Continuous Profiling of Boundary Layer Thermodynamic Structure. To be presented at the Fourth Symposium on Global Change Studies. AMS 73rd Annual Meeting. Anaheim, CA. January 1993. 
Smith, W. L., R. O. Knuteson,. S. A. Ackerman, Ma Xia Lin, and H. E. Revercomb, 1993: Algorithms for Estimating Cloud Optical Properties and Boundary Layer Temperature and Moisture Profiles from ARM Groundbased FTIR Measurements. To be presented at the session on the Atmospheric Radiation Measurement program. AMS 73rd Annual Meeting. Anaheim, CA. January 1993.

\title{
DISCLAIMER
}

\begin{abstract}
This report was prepared as an account of work sponsored by an agency of the United States Government. Neither the United States Government nor any agency thereof, nor any of their employees, makes any warranty, express or implied, or assumes any legal liability or responsibility for the accuracy, completeness, or usefulness of any information, apparatus, product, or process disclosed, or represents that its use would not infringe privately owned rights. Reference herein to any specific commercial product, process, or service by trade name, trademark, manufacturer, or otherwise does not necessarily constitute or imply its endorsement, recommendation, or favoring by the United States Govurnment or any agency thereof. The views and opinions of authors expressed herein do not necessarily state or reflect those of the United States Government or any agency thereof.
\end{abstract}



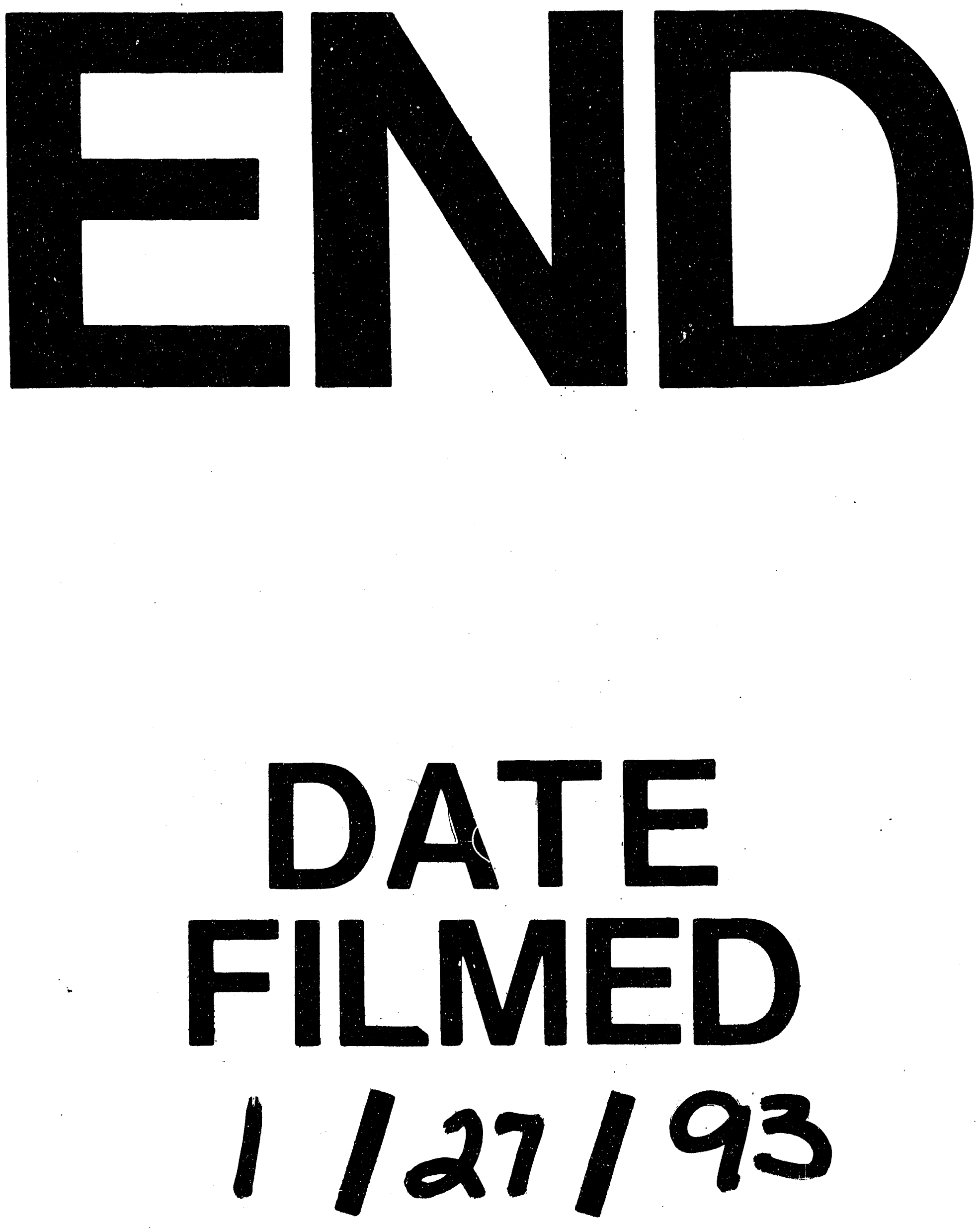
